\title{
A sociologia da saúde nos Estados U nidos, Grã-Bretanha e França: panorama geral
}

\author{
H ealth sociology in the United States, Great \\ Britain and France: a general overview
}

Everardo Duarte N unes ${ }^{1}$

Abstract The aim of this report is to outline a general overview on medical sociology/sociology of health in the U nited States, Great Britain and France from its origins to present days, presenting the most expressive scientific production. The origins of modern medical/ health sociology are situated at different time frames: post W orld War II development in the U nited States, in Great Britain in the 60 s, and in France in 70s. N owadays the study of these national trajectories shows that medical/health sociology is a well-established field with a consistent devel opment and shows diversified subjects and a plurality of theoretical approaches. Key words Medical sociology, Sociology of health, U nited States, Great Britain, France
Resumo 0 trabalho tem como objetivo apresentar um panorama geral da sociologia mé dica/sociologia da saúde nos Estados U nidos, Grã-Bretanha e França, das suas origens até hoje, situando a produção científica mais expressiva desse campo nesses países. A moderna sociologia médica/saúde emerge em diferentes momentos: nos Estados U nidos logo após a Segunda Guerra; na Grã-Bretanha, nos anos 60; e na França, na década de 1970. 0 estudo dessas trajetórias nacionais mostra que, na atualidade, constitui um campo estabelecido e em franco desenvolvimento com uma temática bastante diversificada e uma pluralidade de abordagens teóricas.

Palavras-chave Sociologia médica, Sociologia da saúde, Estados U nidos, Grã-Bretanha, França

\footnotetext{
1 Departamento de Medicina Preventiva e Social, Faculdade de Ciências M édicas, Universidade Estadual de Campinas. Cidade Universitária Zeferino Vaz, 13081-970, Campinas SP. evernunes@uol.com.br
} 
Deixe me convidá-los para seguir adiante, e fazer uma sociologia médica melhor, que seja rica em conteúdo, mais criativa eabrangente, e carregada de significado individual e social; uma sociologia médica que encontre os mais al tos padrões de excelência intelectual e iluminismo social, tanto quanto de zelo e compassividade ( $R$ née C. Fox, 1985).

\section{Introdução}

O objetivo deste texto éacompanhar o percurso da sociologia médica/sociologia da saúde, destacando a sua trajetória nos Estados U nidos, Grã-Bretanha, França, incluindo as análises críticas que foram feitas. Embora este campo apresente, hoje, caráter internacional, selecionamos essas três experiências por expressarem diferentes abordagens deste campo no interior da sociologia.

\section{Estados U nidos}

Na história da sociologia médica/sociologia da saúde, o ponto de referência é a experiência desenvolvida nos Estados Unidos, que, em mais de cinco décadas, conferiram um lugar de destaque a esse campo. M uitos foram os estudiosos que se dedicaram a revisá-lo, pois, à medida que a disciplina avançava em termos de pesquisas empíricas, impunha-se a análise do próprio campo. N esse sentido, há trabalhos que, já no início dos anos 50, propunham esquemas de análise: Straus (1957), Freeman e Reeder (1957), Reader e Goss (1959), Stern (1959). Posteriormente, outros trabalhos seriam realizados, nos anos 60 e70, como os de Reader (1963), Freidson (1962, 1970, 1983), H ollingshead (1973) e continuaram durante toda a década de 1980, imprimindo, nesse período, um caráter bastante crítico em relação à sociologia médica: Bruhn, Phillips e Levine (1985), Cockerham (1983, 1988, 2001), Fox (1985, 1989), Bloom (1986, 1990), M echanic (1989), Levine (1987), Perlin (1992).

Quando se analisam as origens mais remotas da sociologia médica norte-americana, verifica-se que a expressão apareceu em uma conferência de M cl ntire, proferida em 1893 ( $M$ clntire, 1894); reaparece em Blackwell (1902) e, posteriormente, em Warbasse (1909).

As citações acima são parte da história das preocupações com o campo da sociologia mé- dica, mas, sem dúvida, os precedentes sociológicos importantes da disciplina são encontrados nos trabal hos que se produzem a partir do final dos anos 20 e se estendem até os anos 40 , configurando uma primeira fase no desenvolvimento da sociologia médica norte-americana. Esta primeira fase é muitas vezes pouco valorizada, mas não se pode esquecer que os trabalhos sobre problemas sociais e questões específicas sobre a distribuição da doença figuram como importantes temas tratados pela 1a Escola de Chicago, sob a direção de W. I. Thomas (1863-1944) e R. E. Park (1864-1944).

Foi, entretanto, a partir do pós-guerra que a sociologia médica começou a se transformar em atividade regular, quando significantes quantias de recursos federais para a pesquisa sóciomédica tornaram-se disponíveis, em especial as destinadas ao National Institute of $M$ ental $\mathrm{H}$ ealth, que possibilitaram um encontro da sociologia com a psiquiatria, num trabalho quejá havia sido iniciado, em 1939, com as pesquisas conduzidas por Faris e Dunham em Chicago. Destaque-se a pesquisa real izada por um sociólogo (H ollingshead) e um psiquiatra (Redlich), sobre as relações entre classe social e doença mental, cuja importância é sempre citada não somente para os debates que se estabeleceram nos Estados U nidos sobre os centros de saúde mental comunitários dos anos 60, como, também, para outros estudos, tais como o M idtown $M$ anhatann Study, realizado por Srole e colaboradores, trabalhos que são apontados como fundadores (Cockerham, 1988).

$\mathrm{N}$ essa fase de desenvolvimento da sociologia médica, as organizações privadas e federais estimularam a cooperação entre médicos e sociólogos, como foi o caso do programa da Russel Sage Foundation, a partir de 1949, resultando na publicação de dois livros, o de Simmons e W olf (1954) e o de Suchman (1963). Cite-se, ainda, o papel desempenhado pela Fundação J osiah M acy, que captou a importância das intrépidas noções de cibernética, e, logo depois da publicação do livro de W iener, em 1948, auspiciou e organizou conferências sobre 0 assunto. Essas idéias seriam fundamentais para as bases dos estudos sobre a conduta humana que conduziriam à formação do Centro de Estudos Superiores das Ciências da Conduta, em Palo Alto, Califórnia, estabelecido em 1954, com apoio da Fundação Ford. Destaque-se que os métodos científicos da bioquímica e da fisiologia seriam importantes em suas aplicações para o estudo dos efeitos das emoções sobre o comportamento. Com es- 
ses e outros estudos firmava-se uma corrente de pesquisadores que se tornaram cientistas comportamentais.

Badgley e Bloom (1973) oferecem uma detal hada análise da questão da definição de ciência do comportamento - behavioral science, também usada no plural, e dizem que como campo de inquérito, representa uma tentativa de integrar diversas antigas e próximas disciplinas do trabalho universitário dentro de uma abordagem mais integral eatualizada para estudar o homem. Em suas origens está a figura de James E. M iller, líder do grupo original de cientistas da Universidade de Chicago, que procurava criar uma teoria do comportamento, juntando cientistas do campo biológico e social. Para ele, o termo era aparentemente neutro e suplantaria a denominação ciência social, que podia ser confundida com socialismo.

Os anos 50 marcam a presença de uma preocupação com as questões comportamentais, destacando-se a publicação do livro The social system, de Talcott Parsons. Escrito para explicar um complexo modelo funcionalista da sociedade no qual os sistemas sociais são interligados aos sistemas correspondentes de personalidade e cultura, o livro apresenta o capítulo X, intitulado "Social structure and dynamics: the case of modern medical practice", que passará como 0 primeiro texto de elaboração teórica do campo da sociologia médica. Nele, o autor irá desenvolver, na sua conceituação de papéis sociais, a caracterização do papel do médico e do papel de paciente. Para o primeiro, frisa: 0 papel do médico centra-se em sua responsabilidade pelo bem-estar do paciente, no sentido de facilitar sua recuperação da melhor maneira que permita a habilidade do médico (Parsons, 1967). M as, antes, éinteressante verificar como o autor conceitua a doença. Parsons assim se expressa: A doença pode ser considerada um modo de resposta às pressões sociais, entre outras coisas, como um modo de eludir responsabilidades sociais. $M$ as isto, como veremos, pode ter também alguma possível significação social positiva. Quando doentes, as pessoas assumem o papel que, para o autor, tem um conjunto de expectativas institucional izadas e correspondentes sentimentos e sanções. N esse papel, o indivíduo é: isento dos seus papéis sociais normais; necessita ser ajudado; estando em uma condição indesejada, tanto ele como os outros devem retirá-lo dessa situação o mais rápido possível; obrigado a procurar ajuda competente a fim de tratar-se. Dessa forma é que o papel da pessoa doente, agora pa- ciente, articula-se com o do médico. Este, por sua vez, adquire o seu papel, sendo que os critérios de competência técnica no seu desempenho são proeminentes. Além disso, é universalista, funcionalmente específico e afetivamente neutro. Acrescenta que, com relação às variáveis estruturais da ação ( pattern variables) - self versus orientação para a coletividade, o papel do médico situa-se na segunda, visto que $A$ "ideologia" da profissão dá grande ênfase sobre a obrigação de o médico colocar o "bem-estar do paciente" acima de seus interesses pessoais, e vê o "comercialismo" como o mais sério e insidioso demônio que ele tem decombater. Estes são al guns destaques da forma pela qual Parsons encaminhou a discussão e que encontrará muitos adeptos, mas, também, críticos contundentes. Para Frankenberg (1974), em suas conclusões teóricas, Parsonsé, ao mesmo tempo funcionalmente otimista e empiricamente errado. Ele vê as funções latentes do papel de doente, do papel de médico, e sua interação no que concerne com o controle social ea "correção" do desvio. Ele distingue outra vez entreo papel de paciente e o de doente, mas falha de ver todas as implicações contidas nessa diferença.

Sem dúvida, com a obra de Parsons abriase um vasto campo de trabal hos que seriam a marca da sociologia médica norte-americana durante quase duas décadas. $N$ ão se pode esquecer que se inicia neste momento uma das fases marcantes do pensamento sociológico norte-americano: o do estrutural-funcionalismo, tanto o desenvolvido por Parsons, em $\mathrm{H}$ arvard, como o do seu discípulo Robert M erton, em Columbia, que retrata um período áureo da sociologia nos Estados Unidos.

Os anos 50 seriam, também, marcados pelo enorme interesse despertado pela educação mé dica como objeto de estudo de muitos sociólogos, criando, até, uma subárea da sociologia mé dica, a sociologia da educação médica, na qual despontaram trabalhos que se tornaram clássicos, notadamente os de M erton, Reader e Kendall (1957). Poucos anos depois, esse estudo seria confrontado com a notável pesquisa de Becker, Geer, H ughes e Straus (1961), que rompia com a perspectiva funcionalista anterior, trazendo para as pesquisas em educação médica a perspectiva interacionista.

É na Universidade de Columbia que a "sociologia crítica", inspirada por Charles W right M ills (1916-1962), irá aparecer, nos anos 60, mais ou menos no mesmo momento que se formava a 2a Escola de Chicago, que elaboraria outras teorias e metodologias, tendo como princi- 
pais mentores Herbert Blumer, que formularia em 1937 o paradigma do interacionismo simbólico, e Everett C. Hughes (1897-1983), com pesquisas em sociologia do trabalho. Estes farão muitos discípulos, dentre os quais alguns irão se dedicar aos temas da medicina, como Howard Becker (1928-), Erving Goffman (1922-1982), Anselm Straus (1916-1996).

0 advento do interacionismo simbólico será da maior importância, pois provocará o debate com o funcionalismo e estimulará a produção científica na área, incluindo o desenvolvimento da "teoria do rótulo" (labeling theory), com os trabal hos de Goffman (1973) e seu conceito de instituição total, Becker (1963), sobre o desvio; Scheff (1966) estudando o doente mental; Glaser e Straus (1965), tematizando a morte.

Inegavelmente, pela quantidade de estudos empíricos realizados e formulações que os acompanharam, destacam-se, nos anos 60 e início dos 70 , as pesquisas sobre a experiência com a doença, envolvendo estudos relacionados à definição, percepção e reação à doença ( $N$ unes, 1995). Sem dúvida, além da influência que a perspectiva parsoniana irá exercer sobre as pesquisas, a importância de M echanic (1989) , através de seu conceito de "comportamento na doença" (illness behavior) será uma das marcas desse período.

Em relação à sociologia, Cuin e Gresle (1994) apontam que, no início dos anos 70, ela passaria, nos Estados Unidos, por uma acel eração brutal de seu recrutamento e de seu financiamento público (que triplica entre 1970 e 1973, quando atinge 120 milhões de dólares por ano), seguida de uma regressão ainda mais rápida. Em 1970, a ASA (American Sociological Association) incluía mais de vinte comitês; em menos de 10 anos, o número de seus membros dobrou, para atingir a cifra de 14.156, aumentando para 14.387, em 1975 (Bloom, 1986). Ainda nesse momento, contam-se cerca de quarenta associações nacionais e regionais e 200 revistas sociológicas. Os dados citados por Bloom (1986) são interessantes quando comparados com a filiação de membros na Seção de Sociologia M édica da ASA. Assim, desde 1971 (a Seção começou em 1962, mas os dados disponíveis são a partir de 1971) até 1985 , a proporção foi de $7,5 \%$ do total de membros da Associação, sendo que foi crescente, de 4,75\%, em 1971, para 8,6\%, em 1985. Em números absolutos, há um decréscimo de 1980, quando havia 1.018 membros, para 993, em 1985. Quase dez anos depois, em 1994, a Seção de Sociologia M édica tinha 1.160 membros.
Acrescente-se, também, que, por volta de 1972, havia nos Estados Unidos 47 universidades onde se ensinava sociologia médica em nível de mestrado e doutorado.

Q uanto à sociologia médica, a partir do final dos anos 60 irá se perceber uma mudança na perspectiva dos estudos nesse campo. No trabal ho de Samuel Bloom, datado de 1976 (Bloom, 1986), o veterano estudioso da sociologia médica norte-americana apresenta esta tendência, apontando o que havia ocorrido. Assim, esquematicamente, verifica-se que a perspectiva dos estudos passou:

\begin{tabular}{ll}
\hline De & Para \\
\hline $\begin{array}{l}\text { Um esquema de referência } \\
\text { sociopsicológico }\end{array}$ & Análise institucional \\
$\begin{array}{l}\text { Pesquisa de temas sobre } \\
\text { as relações sociais de } \\
\text { pequena escala }\end{array}$ & Sistemas sociais amplos \\
$\begin{array}{l}\text { Análise de papéis em } \\
\text { estabelecimentos limitados }\end{array}$ & $\begin{array}{l}\text { Análise de organizações } \\
\text { complexas } \\
\text { Interesses teéricos básicos } \\
\text { Ciência política dirigida à } \\
\text { sistemática tradução do } \\
\text { de comporises clássicas } \\
\text { conhecimento básico } \\
\text { de processo de tomada }\end{array}$ \\
$\begin{array}{l}\text { Uma persões } \\
\text { relações humanas }\end{array}$ & Análise de estrutura de poder \\
\hline
\end{tabular}

Sem dúvida, essas novas tendências que irão se firmar nos anos 70 serão, também, conseqüência da enorme crítica que se faz à organização dos serviços de saúde, ao desafio dos problemas com as doenças crônicas, à presença dos debates sobre $\mathrm{O}$ acesso ao cuidado médico ( $\mathrm{Me}$ dicare e M edicaid), dos protestos das enfermeiras pela sua posição subal terna na hierarquia médica (Pescosolido e Kronenfeld, 1995). N esse momento é que aparecem, com destaque, os estudos realizados por pesquisadores com formação marxista. D entre estes, citem-se: Navarro (1976, 1982a, 1982b, 1983), W aitzkin e Waterman (1974), Ehrenreich e Ehrenreich (1970), Waitzkin (1998). Basicamente, como apontam os diversos trabal hos nesta perspectiva, os fatores estruturais e políticos são determinantes das doenças que ocorrem na sociedade. Toda a análise que será empreendida por $N$ avarro, por exem plo, enfatiza as características estruturais da sociedade capitalista e o papel funcional da 
organização das instituições de saúde na manutenção do capitalismo. Para White (1991), 0 autor é contra aquelas formas de marxismo tecnologicamente reducionista que dá prioridade às forças de produção. Para N avarro, o conhecimento ea tecnologia médica não têm uma existência separada do capitalismo, ou melhor, eles são os produtos dela e o biologicismo, o cientificismo, o mecanicismo, o positivismo são características intrínsecas ao próprio conhecimento médico sob o modo capitalista de produção. A análise de $N$ avarro foi criticada de diversas maneiras: ora porque seus argumentos são muito gerais, ora porque sua visão é reducionista; porém, é em relação ao papel do Estado que a sociologia da saúde de inspiração marxista recebeu as críticas mais contundentes. De um modo geral, as relações de classe são fundamentais nas explicações que buscam trazer para o campo da saúde as formulações marxistas. Para White (1991), o modelo é monolítico e omite o político, o sociocultural enão permite compreender a complexidade do Estado na distribuição do cuidado à saúde. Para Reidy (1984), nos trabalhos de Navarro ocorre um uso persistente de explicações funcionalistas do papel do estado em geral e dos serviços de saúde e médicos em particular.

Waitzkin (1998) retomaria a sua análise sobre as práticas de saúde e suas relações com 0 capitalismo, especialmente sobre a ideologia que perpassa a sociedade norte-americana, que favorece a managerial decision. Coloca em discussão as ambigüidades do gerenciamento e a sua construção ideológica. Ressalta como a "me dicina baseada em evidência" torna-se um instrumento dessa prática ao formular clinical guidelines usadas para monitorar os médicos em suas decisões clínicas, a partir da consideração que elas imprimem cientificidade ao processo de conhecimento. Para os administradores, a sua utilização serve para aprovar ou desaprovar procedimentos clínicos específicos, na dependência dos tipos de cobertura dos seguros de saúde. Não se pode deixar de mencionar que, nos anos 70, Waitzkin, ao analisar criticamente al guns autores, notadamente Parsons e M echanic, volta-se para compreender o relacionamento médico-paciente como um processo que se realiza entre duas pessoas, mas como parte integrante da organização do sistema de saúde. Este tema é retomado no livro The politics of medical encounters: how patients and doctors deal with social problems, tornando-se um dos mais influentes trabalhos no campo das relações paciente-provedor. Com rigor científico, confronta as dificuldades metodológicas e os problemas teóricos de estudar a ideologia médica, o controle social profissional, e a linguagem das relações na medicina (Chen, 1998).

Para se compreender os mais recentes encaminhamentos da sociologia médica norte-americana, é conveniente retornar ao esquema de Bloom (1986) apresentado neste texto. 0 fato de configurar dois campos não significa que não se estejam realizando importantes pesquisas no campo considerado mais micro e relacional. Esses trabalhos, do final dos anos 70 e da década de 80, têm tratado de temas tais como: internato e residência; relações interpessoais em estabelecimentos, como, por exemplo, cuidado intensi vo neonatal, ou relações médico-paciente; aspectos sociopsicológicos do comportamento na doença; de outro lado, a atenção para questões sobre a organização da prestação de cuidado à saúde, dos determinantes organizacionais de qualidade do cuidado, representada pelas organizações corporativas e sindicais.

Do ponto de vista de uma análise crítica sobre a sociologia médica que vinha sendo realizada nos Estados U nidos, M anfred Pflanz (1974) expôs, no início dos anos 70, como essa disciplina, que havia apresentado um rápido desenvolvimento, entrava em uma fase que provocava intenso desencanto, como parte do descontentamento geral, etambém pelo fato de não estar tratando de importantes problemas. Aponta em seu trabal ho que a "dificuldade de encontrar uma definição válida para a sociologia médica" constitui um problema essencial. Argumenta que, em termos gerais, o princi pal objetivo da sociologia médica é melhorar as condições de vida para os seres humanos. Isto inclui analisar as desigualdades na distribuição e freqüência das doenças, assim como na provisão e utilização dos serviços de cuidado à saúde. Nessa perspectiva, 0 autor avança, dizendo que compete a ela não somente prover achados científicos, mas, também, elaborar soluções práticas em termos das políticas sociais e de saúde, que foram indicadas pelas pesquisas. Ela estaria impregnada por uma orientação frente a valores que conflitam com a medicina e com os médicos. Além desse aspecto, que teria levado a sociologia médica a reforçar o monopólio médico, Pflanz (1974) afirma que não se cumpriu a expectativa pós-parsoniana da elaboração de uma "grande teoria que seria também extensiva à sociologia médica" e que esta se restringiu à teoria de médio al cance, e trabalhando com hipóteses mais restritas, que em anos mais recentes corre- 
ram atrás de pretensioso conceito de "modelos". Contudo, nos limites há esperanças que produtivas trocas de teorias possam tomar lugar entre a sociologia geral e a médica. 0 autor não nega a existência de considerável quantidade de achados empíricos, mas há a necessidade de avançar em termos do estudo da distribuição desigual das doenças; nesse sentido, critica a epidemiologia por não ter desenvolvido teorias úteis sobre a causalidade social da doença.

Anteriormente às criticas feitas por Pflanz (1974), Freidson (1970) dizia que, embora a sociologia médica tivesse al cançado em tempo relativamente breve o caráter de uma "especialidade reconhecível", ela havia se esparramado através de um vasto conjunto de áreas substantivas sem qualquer óbvia "rationale" em sua organização, e as abordagens dos sociólogos médicos para seus estudos tinham sido extremamente variados, desafiando qualquer integração. Citava que, naquele momento em que escrevia, dois livros publicados anteriormente (entre os quais um de sua autoria) eram extremamente sel etivos; um era o texto de David M echanic M edical soci ology (1968), que se limitava largamente ao estudo dos aspectos sociais da doença e aos processos sociais que conduzem à adoção do papel de doente; e outro o de Elliot Freidson Profession of medicine (1970), que se limitava à análise da profissão médica. Sem dúvida, al guns dos pontos anotados por Freidson podem ser apontados como motivadores da insatisfação relatada por Pflanz, ou seja: certos temas não estavam presentes na agenda dos pesquisadores, a falta de um marco teórico mais claro e de uma análise crítica dos processos sociais na organização e distribuição do cuidado à saúde. Por isso, a importância da observação de Bloom ao esquematizar a mudança de enfoques.

$\mathrm{N}$ ão se pode negligenciar a importância da contribuição trazida por Freidson, especialmente ao cunhar o conceito de professional dominance (1970), que será amplamente utilizado nos anos seguintes, como já o havia sido a sua noção de lay referral system (1960). Ao retomar a idéia parsoniana de "papel de doente", Freidson irá estabelecer os seus limites. Para Freidson, o esquema parsoniano aplica-se às pessoas da classe média norte-americana e européia e não àquelas pessoas que estão fora da atenção médica profissionalizada (Freidson, 1970). Em seu livro Profession of medicine, Freidson (1970) irá desenvolver uma série de idéias em torno dessa questão, assinalando a necessidade de construir diferentes papéis de doente, de acor- do com a gravidade da doença, seu caráter estigmatizante, ser doença curável ou incurável. $M$ ais ainda, destaca que, assim, é possível discriminar a variação das crenças, conhecimentos e costumes, enfatizando o caráter temporal e cultural dessas variações. Tendo se dedicado inicialmente a pesquisar o relacionamento médico-paciente, Freidson (1970) volta-se em seguida para o médico, assumindo ter ele um papel dominante nesse relacionamento, analisa a profissão médica considerada protótipo do profissionalismo, constituindo o anseio de todas as outras ocupações na área da saúde. No que se refere ao conceito de professional dominance, basicamente assenta-se no status e poder profissional que são concedidos ao médico, aos quais se juntam as suas habilidades no uso do que se denomina dinical freedom. Esses atributos acabam moldando todo o sistema de saúde e as suas práticas.

Como já foi assinalado, com os anos 70 inicia-se uma retomada dos aspectos estruturais e o aparecimento de uma sociologia da saúde de caráter mais crítico. Entretanto, como irá escrever Fox (1985), certas fal has continuavam a persistir na sociologia médica norte-americana. Para essa pioneira da sociologia médica, a sociologia médica apresenta uma característica paradoxal na forma em que tem se desenvolvido. Sua effera é potencialmente vasta: o número de cientistas sociais que tem sido atraído para a sua órbita é impressionantemente amplo; a literatura que tem sido gerada é extensa. Entretanto, vistos mais de perto, os fenômenos, o meio e os temas com os quais os sociólogos da medicina têm estado interessados são relativamente restritos e seletivos (Fox, 1985). A socióloga enumera que nós sociólogos temos estudado pacientes e famílias menos do que nós gostaríamos de acreditar e mais profissionais médicos do que gostaríamos de supor, ou provavelmente considerar apropriado. D entro deste esquema de referência, nós temos dirigido uma larga porção de nossa atenção para os médicos, muito menos para as enfermeiras, e uma negligenciável quantidade para muitos outros grupos de profissionais, semiprofissionais, e não profissionais que se dedicam ao trabalho médico ou medicamente orientado. Enfatiza, ainda, que de modo geral, temos estado mais interessados com doenças mentais do que somáticas, com doenças do que com saúde, e somente com um pequeno número de doenças e desordens que atingem homens, mulheres e crianças. Durante as três últimas décadas, temos devotado milhares de páginas para debater os méritos e deméritos dos con- 
ceitos do papel de doente e do comportamento frente à doença. Em nossas discussões sobre profissionais médicos, temos estado preocupados, se não obcecados com a dominação profissional do médico, a institucionalização de seu individualismo e autonomia, sua insistência sobre a auto-regulação e autocontrole, seu senso de hierarquia, seu paternalismo e seu poder sobre os corpos, mentes e comportamento dos pacientes, assim como sua soberania econômica e política. Situa, também, que há uma extensa literatura que pesquisou a perda de ideal ismo do médico, 0 seu progressivo cinismo, impessoalidade, o treinamento para enfrentar as incertezas, limites e erros no trabalho. De outro lado, o próprio estudo do hospital, com al gumas exceções (Goffman, 1961; Fox, 1959, por exemplo), tem sido tratado mais como uma organização al tamente burocratizada e formal do que como um mundo com muitas características distintivas e muitos pathos humanos. Critica, ainda, a tendência em se fixar em certos conceitos e usá-los de forma mais retórica e ideológica do que como catalizadores para aproximações empíricas detalhadas. N esse sentido, cita frase como the coming of the corporation e the medical-industrial complex, que, na opinião de Fox (1985), brevemente substituirão a "professional dominance" (Freidson, 1970), tema que tem sido continuamente invocado nos últimos anos. Fox (1985) finaliza, dizendo que temos sido críticos da medicina, tanto quanto, se não mais, observadores sociais da medicina. Acentua que muitos dos estudos feitos têm tido um caráter mais estrutural do que cultural. Para que as suas críticas não sejam vistas como "indevidamente injustas e dolorosas", Fox diz que as razões de sua análise são as de apontar as lacunas e temas de pesquisa não desenvolvidos na sociologia médica. Dentre estas, aponta: a feminilização da profissão médica; as mudanças demográficas na composição de pacientes e na natureza e freqüência dos problemas de saúde; as condições humanas dos profissionais de saúde, incluindo os mecanismos de defesa e de enfrentamento no trabaIho; o estudo da profissão da enfermagem, as concepções sociais e culturais das doenças; a retomada de estudos sobre o hospital, especialmente voltados para as "comunidades ocupacionais" formadas pelos "não-médicos", paramédicos, pessoal de manutenção, transporte, etc. Diz que, ao lado de estudos macro sobre as implicações políticas e econômicas das práticas médicas, há necessidade de estudos etnográficos que forneçam dados sobre o mundo inter- no do hospital em termos sociais, humanos e culturais. Destaca que não somente a medicina alopática deve ser alvo de estudos, mas, também, a medicina alternativa, e, como tem ocorrido este movimento, associando o movimento na saúde aos movimentos sociais mais amplos. A bioética e o desenvolvimento de uma sociologia da pesquisa biomédica seriam outros dois temas da maior relevância para a pesquisa dos cientistas sociais na área da saúde.

Deve-se lembrar que a análise crítica a que vinha sendo submetida a sociologia médica ressaltava, em especial, que esse campo apresentava "escassez de trabalho teórico", como escreve Johnson (1975). 0 caráter modesto das contribuições teóricas advindas da Sociologia M édica fez com que fosse vista como tributária da medicina, utilizando o modelo médico da doença e incorporando, sem críticas, definições médicas dos problemas. Essas conclusões foram alcançadas por Gold (1977), quando estudou 515 artigos publicados no Journal of $\mathrm{H}$ ealth and Social Behavior, período de 1960-1976 e verificou que aproximadamente $60 \%$ estavam primariamente voltados para os pacientes - suas atitudes, atributos e comportamento. Ao criticar este artigo, Greene (1978) lembrava que a autora não havia tratado daqueles estudiosos que se voltaram para a análise crítica do sistema de saúde. Gold (1978), ao replicar os comentários, reafirmava que o fato de ter encontrado aqueles valores evidenciava que o viés médico era um problema para o campo da sociologia médica e que havia necessidade de se ol har além dos atributos dos pacientes e além do sistema de cuidado à saúde, ou seja, o contexto social mais amplo.

No início dos anos 90, Perlin (1992) estabeleceria uma categorização de como havia se organizado o amplo espectro de interesses dentro do campo da sociologia médica, dividindo os pesquisadores em duas classes: os structure see kers e os meaning seekers. Para este autor, a própria sociologia, que no passado havia sido dominada por duas ou três teorias, encaminha-se, hoje, para muitos paradigmas distintos. Como escreve: As linhas cruzadas que cobrem a face da sociologia na atualidade refletem, naturalmente, a especialização de interesses importantes que têm emergido gradualmente em recentes anos, os refinamentos de perspectivas teóricas, e o desenvolvimento de metodologias sofisticadas. Da mesma forma, esse pluralismo intelectual, que tem trazido vigor e vitalidade para o campo, tem concorrido para a multiplicação de subcampos e especialidades na sociologia, atingiu a sociolo- 
gia médica, "espelhando-se na disciplina mais ampla" (Perlin, 1992). Assim, a sociologia médica já não pode ser considerada uma subespecialidade unificada, se é que foi algum dia, como diz esse autor. Cita um elenco de pesquisas que abordam: as políticas nacionais de saúde; a reabilitação das doenças e da incapacidade; os profissionais que cuidam da saúde, seu treinamento, socialização e comportamento; a organização formal dos estabelecimentos de saúde; estigma; as origen s e conseqüências do estresse; ética médica; comportamento de risco na saúde; utilização dos serviços de saúde; Aids; álcool e abuso de drogas; epidemiologia social; a morte e o morrer; a história social das práticas de saúde e normas. Chama a atenção que, do ponto de vista metodológico, os métodos qualitativos equantitativos têm sido ampla ediversificadamente utilizados. D e outro lado, o campo compõe-se não somente por sociólogos mé dicos, mas por profissionais com formações as mais diversas, por exemplo, psicologia social, bioestatística, ou em áreas do conhecimento específicas, tais como: família, organização das profissões, ciclo da vida; estratificação social, trazendo para o campo da sociologia médica as tradições intelectuais de outras áreas do conhecimento. Porém, sob a superfície desta diversidade, há uma considerável consolidação de orientações entre os sociól ogos médicos Perlin (1992). Para o autor, de um lado estão os sociólogos que procuram revelar a estrutura da vida social esuas conseqüências para a saúde; de outro lado, há aqueles que procuram revelar o significado da vida social e seus reflexos sobre a saúde. Assim, para simplificar, chama os primeiros de structure seekers e, os segundos, de meaning seekers. Enfatiza, entretanto, que não há grupos concretos que se situem dentro dessas fronteiras, sendo provável que muitos sociólogos não se identifiquem como pertencentes a um ou outro grupo. São usados como termos de referência e não descrevem as nuanças e sutilezas que permeiam os grupos de pesquisadores que possam ser incluídos nessas categorias.

Com relação às questões de caráter metodológico, cite-se o excelente artigo de M echanic (1989), "M edical sociology: some tensions among theory, method and substance". 0 autor, como ele próprio relata, iniciara as suas pesquisas de campo, em hospitais psiquiátricos, em 1956, e pôde acompanhar no treinamento de estudantes as mudanças ocorridas nesses cenários e o que selecionar para observar. 0 autor destaca que a seleção do que observar "depende substancialmente da biografia social do observador". Constitui este trabalho uma elaborada reflexão sobre a pesquisa qualitativa e quantitativa e, para o autor, a utilização de diários constitui uma ponte bastante promissora entre surveys e pesquisas qualitativas.

Além dos importantes pontos levantados acima, os anos 90 irão ser o cenário para o florescimento de "novas idéias", como escreveu Light (1992). Um pouco na linha de Levine (1995), esse autor intitulou a sua Introdução em um número especial do American Journal of Sociology (1992) de "Strengthening ties between specialties and the discipline". Ao apresentar uma série de trabalhos, pôde observar que eles "estendiam o domínio do campo, ou traziam uma refrescante perspectiva", rompendo a especial ização, pois a ênfase na especialização, embora trouxesse a possibilidade de "um dado grupo de especialistas refinarem seus métodose idéias" (Ligth, 1992), concorria para que eles se tornassem auto-referentes e não mais sentissem a necessidade de contribuir para o estudo acadêmico mais amplo da vida social. A ssim fazendo, eles também se tornaram cada vez menos interessados em outros sociólogos. Conclui que tanto perde a disciplina mais ampla, como a especialidade. E isto é mais grave quando se trata de especial idades de aplicação, como a sociologia da educação, médica, ou dos esportes, "que necessitam da força de teorias e métodos mais amplos para informar seu trabalho".

$\mathrm{Na}$ organização, os artigos que conformam este número da revista foram agrupados em duas amplas temáticas - "As implicações sociológicas da regulação e dos mercados" e "Poder profissional e trabalho profissional" - e procuram estabelecer um diálogo com variáveis sociológicas e com a literatura ou revisam importantes conceitos do campo. A diversidade das temáticas abordadas inclui desde os "paradoxos da intervenção liberal", às "teorias sociológicas e econômicas de mercados", à "reestruturação dos padrões de dominação das elites", à "dinâmica do controle profissional", às "percepções dos médicos quanto à incerteza", às "relações entre religião, incapacidade, depressão e morte"; às "relações de poder e situação de saúde de afro-americanos" e "além da escolha racional na busca de ajuda".

Sem dúvida, como pode ser visto nesta exposição, o final dos anos 80 e os anos 90 serão para a Sociologia M édica norte-americana um momento de profunda reflexão sobre o próprio campo, em uma análise onde a questão teóri- 
ca e metodológica estará presente, exatamente quando se percebem acentuadas mudanças tanto no interior da subdisciplina, como no campo mais amplo da sociologia, e quando, também, transformações gerais da sociedade norte-americana e específicas no campo da saúde tornamse cada vez mais presentes e acentuadas.

Nesse sentido, os autores retomam a discussão, já em parte apontada neste texto, ou seja, que, embora haja uma grande diversidade temática, há questões antigas que necessitam ser revistas, assim como, com a emergência de novos problemas, reativa-se a busca de quadros de referência teórica que embasem as investigações. Pescosolido e Kronenfeld (1995) dirigem as suas preocupações para os estudos que repensem as relações entre sociedade e medicina, mas também para o fato de que é necessário que os sociólogos médicos reavaliem suas perspectivas quanto a sua disciplina, as outras ciências sociais, as ciências biomédicas e o público. Essas questões se adensam na medida em que as condições sociais sofrem rápidas mudanças.

Também Gray e Phillips (1995), ao analisarem as conexões entre a sociologia médica e a política de saúde, chamam a atenção para o fato de que se deve verificar o impacto da primeira sobre a segunda, especialmente porque este impacto tem sido limitado por três ambivalências: a do sociólogo; a da carreira acadêmica; e a da pesquisa em política de saúde, que tem se tornado um campo distinto de pesquisa. Como visto acima, aqui, também, sente-se a necessidade de uma reorientação do sociólogo médico, tanto na escolha dos problemas, como na seleção das variáveis a serem pesquisadas, num sentido de tornar a pesquisa mais aplicada e, portanto, de maior impacto.

Dentre os temas considerados relevantes destaca-se, ainda, o da construção social do diagnóstico e da doença, como abordado por Brown (1995). No texto que trata do assunto, 0 autor revisa as três principais versões do construcionismo social que têm sido aplicadas à sociologia médica: a etnometodologia e o interacionismo simbólico, a de tradição européia é exemplificada pelo trabal ho de Michel Foucault, e a versão relacionada à sociologia da ciência, tomando como exemplo o trabalho de Bruno Latour. Para Brown (1995), o construcionismo social é uma síntese do interacionismo. Deve-se ressaltar que a construção social do conhecimento médico e a construção social da doença são distintas. A primeira trata das origens das crenças profissionais e do diagnóstico, a segun- da, com a experiência da doença (illness). Afirma Brown (1995) que a construção social de um fenômeno envolve uma multiplicidade de forças sociais que se combinam na criação e modificação do fenômeno. Dessa forma, envolve $o$ impacto das estruturas subjacentes e, por isso, o construcionismo social pode ser uma perspectiva para analisar três níveis de conhecimento e ação: o micro (autoconsciência, ação individual, comunicação interpessoal); médio (hospitais, educação médica); macro (sistema de cuidado à saúde, política nacional de saúde). Para a elaboração de uma sociologia do diagnóstico médico, a perspectiva construcionista é vista como fundamental. Básica para isto é a distinção entre o conceito de disease e illness; “0 primeiro é um fenômeno mais biomédico, embora fortemente afetado por forças sociais"; 0 segundo reflete mais um fenômeno subjetivo. As mesmas forças que afetam a distribuição da doença (disease) também levam a diferentes percepções, concepções, e experiências da situaçãa de saúde (Brown, 1995). 0 diagnóstico é central para o controlesocial, pois "dar um nome" éfreqüentemente o ponto de partida para rótulos sociais, como diz Brown, é a voz da medicina, em contraste com a "voz do mundo da vida". 0 autor desenvolve todo um quadro teórico e modelos analíticos para se entender o processo de construção social da doença que não serão analisados neste relato. D estacando a questão da experiência da doença é importante lembrar que Zola (1966) expunha que diferenças na experiência da doença originam-se de percepções e interações sociais mais amplas, tais como crises interpessoais, da interferência percebida com as relações sociais ou pessoais, apoio social da família e amigos, sanção por parte de um ou outro membro da família, interferência percebida da atividade do trabalho ou física, a temporalização (percepção de sintomas num espaço de tempo). Deoutro lado, Brown (1995) comenta que "nem toda doença (illness) experienciada é o resultado de uma doença particular"; cita, ainda, que "a experiência leiga com a doença não pode ser completamente separada dos elementos da interação clínica". Para este autor, "a experiência da doença está de forma freqüente inextricavelmente amarrada aos problemas estruturais", por exemplo as experiências no campo das práticas obstétricas, como presença dos pais no momento do nascimento, a importância do movimento feminista em seus esforços para "quebrar as atitudes e práticas patriarcais, e instituir alternativas centradas na mulher" em relação ao 
sistema de cuidado à saúde, que levam o autor a falar em "uma forma sociopolítica de experiência com a doença" e de "experiências leigas que são construções e produções sociais coletivas da realidade". Ao retomar a importância da experiência do paciente, Zola (1991) enfatiza a importância de uma "sociologia do corpo", ou seja, não a criação de um novo campo, mas a valorização das "experiências com o corpo", na mesma dimen são que se val oriza na pesquisa a classe social, a etnicidade, gênero, raça, idade, etc.

Quanto aos estudos que se centram nas condições sociais como causas de doença, Link e Phelan (1995) defendem a posição de que, em sua maioria, as pesquisas têm se dedicado aos fatores de risco que são vistos como causas relativamente próximas das doenças, tais como dieta, nível de colesterol, exercícios, etc. Os autores questionam a ênfase sobre os fatores centrados no indivíduo e oferecem para discussão dois esquemas de referências conceituais que ajudem a pesquisa, ou seja, a importância de "contextualizar" os fatores de risco e que algumas condições sociais podem ser "causas fundamentais" da doença.

Outro tema que, como vimos, atravessa a sociologia médica, praticamente desde as suas origens, é o estudo sociológico das profissões, em especial da profissão médica. $\mathrm{Na}$ atualidade, estes estudos voltam-se para a dinâmica profissional e a natureza das mudanças que estão ocorrendo no trabalho médico, como pode ser visto na revisão feita por $\mathrm{H}$ afferty e Light (1995). Para eles, dentre outras discussões, deve-se repensar se a autonomia deve permanecer como tema central para se entender a dinâmica profissional. Apontam que o abuso de suas prerrogativas, suas falhas em controlar o próprio trabalho e a revolta dos usuários ( no original: buyers) são importantes fatores para rever as antigas categorias que definiam a profissão médica, incluindo o movimento que visa avaliar a qualidade dos serviços clínicos e a adoção dos guidelines e protocolos que podem facilitar a perda do controle da medicina sobre as atividades clínicas. A emergência do conceito de accountability - responsabilidade - e a sua convivência com a discrição clínica e autonomia seria um tópico importante a ser pesquisado. Conceitos como o de "incerteza médica" e a da ambigüidade no trabalho médico, tão caros aos pioneiros pesquisadores das profissões, necessitam ser vistos, agora, no contexto dos avanços do conhecimento científico, ou seja, possibilitam mais certezas ou criam uma "nova arena de in- certezas"? Lembram, também, que há estudos que já mostram o número crescente de physician executives (médicos executivos). Além desses temas, há necessidade de investigações que trabalhem com o "ambiente regulatório" da prática, ou seja, as regras que emanam do governo eque atingem o médico. Há questões de nível macro, como também aquelas que envolvem como estão sendo reconfiguradas as várias profissões de saúde.

Por mais extensa que tenha sido a temática exposta até aqui, ela não se esgota nesses assuntos; acrescente-se, por exemplo, os relacionados à saúde mental (Cook e W rigth, 1995) com os estudos sociológicos em dois temas: 1 ) as condições de vida das pessoas com graves desordens mentais e 2) a organização social do tratamento. Para o primeiro tema, volta a ser importante pesquisar os efeitos do estigma, ou melhor, de se tentar desenvolver uma teoria da desestigmatização, para se aquilatar os efeitos da legislação e das formas de serviços mais recentes; pesquisar a integração à comunidade e as redes sociais, para se ter mais clara a questão do apoio social; pesquisar os movimentos dos usuários de serviços e das famílias envolvidas nos processos de ajuda, assim como investigar as formas de controle social e de tratamento, em especial os baseados em psicofármacos. Dentre os temas sobre a organização social do tratamento estão incluídos estudos sobre os custos, análise de processos jurídicos que envolvem doentes mentais encarcerados - "criminalização" e pesquisas que façam análises críticas do processo de diagnóstico psiquiátrico.

\section{Grã-Bretanha}

O desenvolvimento da sociologia médica na Grã-Bretanha apresenta características bastante interessantes, pois se na atualidade mostra um impulso muito grande, teve em suas origens que enfrentar muitos problemas. Reid (2000) lembra que a sociologia e outras ciências sociais foram introduzidas no currículo médico como disciplinas dignas de atenção médica em 1944 e, embora a sociologia já fizesse parte da comunidade acadêmica nos Estados U nidos e Alemanha por muitas décadas, na Grã-Bretanha tinha progredido pouco desde os trabalhos de Sidney W ebb (1859-1947) e Beatrice W ebb (1858-1943) e de alguns outros sociólogos como Charles Booth (1840-1916), Patrick Geddes (1854-1932), Vitor Branford (1864-1930), 
estes três que realizaram pesquisas associando a aritmética política à estatística social; Francis Galton (1822-1911) com seus estudos biodemográficos, que marcam a sociologia inglesa, e Leonard T. Hobhouse (1864-1929), que, ao ministrar um curso de sociologia em 1907, tornouse o primeiro professor de sociologia em uma universidade na Grã-Bretanha, a University of London, sendo, também, considerado o pai da sociologia teórica. M as, como analisa Cuin e Gresle (1994:129-130), divididos em múltiplos clãs, dilacerados por ambi ções contraditórias, na falta de um consenso mínimo sobre o conteúdo da disciplina (sessenta e uma definições da sociologia foram propostas entre 1905 e 1907, por exemplo), é compreensível que os sociólogos britânicos - ao contrário dos etnólogos e apesar de seus notáveis trabalhos de campo - tenham demorado muito tempo para se "profissi onalizar", o que certamente não ocorreu antes do fim da Segunda Guerra M undial. Podem ser citados como relevantes a fundação da London School of Economics, em 1895, e a criação da Sociological Society of London, em 1903, mas somente em 1915 é que surge a British Sociological Association, sendo apontado como um fato importante que impediu um rápido desenvolvimento da sociologia na Grã-Bretanha a oposição das universidades de 0 xford e Cambridge a um estilo de pensamento social que se opusesse à hegemonia da filosofia política herdada do século 19 (Cockerham, 1983). Como é visto por Cockerham, a falha da sociologia britânica em ganhar uma posição segura em 0 xford e Cambridge durante o início do século 20 não foi um fato incomum na experiência européia. A institucionalização da sociologia nos sistemas universitários foi forte somente na América. Sem dúvida, foi com Hobhouse, Ginsberg, M annheim e Titmus que se criou uma tradição de estudos que iriam fazer com que a sociologia britânica prosperasse no pós-Segunda Guerra.

É nesse momento que a sociologia médica irá iniciar os seus passos e embora o British $\mathrm{Na}$ tional Health Service, criado em 1948, tivesse prescindido do envolvimento dos sociólogos, e as instituições médicas não vissem as contribuições da sociologia como relevantes, a não ser para a epidemiologia social, foi o campo médico e não a sociologia acadêmica que estimulou o desenvolvimento da sociologia médica. Cockerham conta que em 1956, os cinco sociólogos que trabalhavam em tempo integral organizaram o primeiro encontro profissional e a partir deste pequeno grupo a Seção de Sociologia M édi- ca da British Sociological Association evoluiu para se tornar a maior seção da BSA. Somente no final dos anos 60 é que se percebe um impulso para a estruturação do campo, com a realização da primeira conferência, em York, que reuniu cerca de 60 sociólogos médicos, assinalando o nascimento do M edical Sociology Group, dentro da BSA. Em 1970, é publicada a primeira edição do M edical sociology in Britain: a register of research and teaching e, em 1973, inicia-se a publicação do Boletim (M edical Sociology N ews) do Grupo de Sociologia M édica da BSA. Em 1976, a conferência anual da BSA irá tomar como tema a "Sociologia da saúde e da doença", evidenciando que os sociólogos passam a encontrar progressivamente respeitabilidade dentro de duas esferas diferentes - aquela da sociologia acadêmica, e aquela da medicina (Reid, 2000).

Recuperando a produção que se inicia nos anos 60, verifica-se que o primeiro livro-texto foi publicado em 1962, por M. Susser eW. W atson, denominado Sociology in medicine, oito anos após o trabalho americano de Simmons e Wolf (1954) Social science and medicine. Outras três publicações importantes aparecem na década de 1970: Robinson $(1971,1973)$ e Tuckett (1976); os dois primei ros tratam, respectivamente, do processo de setornar doentee das relações entre os pacientes e a prática médica; 0 terceiro é um extenso livro-texto de sociologia médica que, além de uma detal hada introdução sobre esse campo de conhecimento, traz capítulos escritos por sociólogos ingleses, como George Brown, David Field, Peter Draper e outros, sobre família, casamento e suas relações com a doença, trabal ho e estilos de vida, o processo do adoecimento, a organização dos hospitais, a organização do serviço de saúde, as causas sociais da doença, a definição social do adoecimento. Cumpre destacar que esses estudos tiveram como antecedentes os realizados por $M$ argot J efferys (1916-1999), pioneira da sociologia médica na Grã-Bretanha. George Brown, citado aci$\mathrm{ma}$, vinha desenvolvendo, desde o final dos anos 60 , importantes pesquisas sobre a esquizofrenia e sobre as origens sociais da depressão.

U m aspecto que sempre é referido quando se analisam as origens da sociologia médica britânica é o fato de ela ter estado fortemente presa à pesquisa aplicada dentro do campo médico. Durante os anos 70 e início dos anos 80, um tema que persiste para os sociólogos éo de definir as fronteiras da subdisciplina num contexto institucional de retração de empregos e de crescimento do número de estudantes de gradua- 
ção e de uma espiral descendente nos financiamentos públicos (Annandale e Field, 2001). A retomada do crescimento ocorreria no final dos anos 80 e, como assinalam Annandale e Field hoje, a sociologia médica britânica está "firmemente estabelecida como uma disciplina acadêmica". Prova dessa maturidade foi a publicação, a partir de 1979, do periódico Sociology of $\mathrm{H}$ ealth and IIIness, de reconhecimento internacional, que foi precedido pelo Social Science \& M edicine, publicado desde 1978. Para esses autores, uma característica permanente desse campo é que as pessoas envolvidas trabal ham em diversos locais, tais como departamentos de ciências sociais universitários, departamentos de enfermagem, escolas médicas, unidades de pesquisa e no N ational Health Service. Isto capacita a sociologia médica a "responder com sucesso as agendas políticas emergentes e as agências de fomento". Entretanto, como salientam, "a subdisciplina tem sido menos bem-sucedida em dirigir-se aos debates sociológicos mais amplos". Esta crítica já havia sido feita por Stacey e Homans (1981), ao apontarem que, embora o campo fosse bastante ativo, não apresentava maiores contribuições teóricas e metodológicas, faltando-Ihe um embasamento mais refinado. A reversão desta situação estaria ocorrendo a partir dos anos 90 , refletindo "um interesse crescente com os temas da saúde inseridos no campo da sociologia acadêmica e da sociedade mais ampla". De um modo geral, os estudiosos da história da sociologia médica/sociologia da saúde e da doença na Grã-Bretanha, ao se reportarem às áreas temáticas que têm prevalecido nesse campo, observam que elas refletem, mesmo considerando as mudanças conceituais, as relações entre a sociologia acadêmica, a medicina e a política de saúde, tais como: anál ises da experiência da saúde e da doença, desigualdades na saúde (especial mente relacionadas à classe social, e, mais recentemente, gênero, "raça" e idade), e a provisão de cuidados de saúde (formal e informal). Para Annandalee Field (2001), em cada uma destas amplas áreas, diferentes temas se revelam em resposta aos desenvolvimentos dentro da ciência médica, sociologia, teoria social, novas agendas públicas, ea emergência de novas doenças e mudanças nos padrões de saúde e doença que caracterizam os anos 90. Em trabalho anterior, Annandale (1998) elabora uma detal hada incursão nas relações entre a teoria social e a sociologia da saúde e da doença, "cartografando os terrenos intelectuais de onde emerge a sociologia da saúde e da doença contemporâneas". Sua atenção volta-se para a ortodoxia que emergiu em torno das perspectivas da economia política e do interacionismo simbólico nos anos 70 e 80, sua posterior revisão com 0 advento das abordagens foucauldianas do construtivismo social e das teorias sociais pós-modernas, inclusive a teoria feminista. Da mesma forma, as coletâneas de Scambler e Higgs (1998), assim como a organizada por Field e Taylor (1998), exemplificam a riqueza temática e analítica oferecida pela moderna sociologia médica britânica.

\section{França}

Kristina Orfali (2001), ao analisar os "paradoxos franceses" na área da saúde, cita uma passagem que nos encaminha na elaboração de alguns aspectos da sociologia médica na França. Para Orfali (2001), é surpreendente o lento e recente desenvolvimento da sociologia médica no contexto de uma nação onde nasceu a sociologia, mas também a clínica. É curioso que a França de Bichat, Laennec e Claude Bernard não desempenhou um papel mais inovador em fazer do "adoecimento" e da "medicina" os objetos de estudo sociológico. Ao situar os anos 70 como 0 momento importante no desenvolvimento de uma sociologia médica, não se pode deixar de citar alguns precedentes, que, embora se situem num plano diferente das abordagens das trêsúltimas décadas, constituem parte do pensamento francês em saúde. Lembramos o trabalho sociológico exemplar de Émile Durkheim (18581917), 0 suicádio, marco da sociologia ocidental, de 1879; os estudos epidemiológicos de Louis René Villermé (1782-1863) sobre mortalidade e mortalidade infantil, que datam das primeiras décadas do século 19 e sobre "o estado físico e moral dos operários têxteis", de 1840; os trabalhos dos higienistas, como Philipe Buchez (1796-1865), que caracterizam um momento importante do pensamento social relacionado à medicina. Jacques M aître (1973), ao se referir a esses e a outros trabal hos produzidos no século 19 , quando comparados com o que se escreveu a partir dos anos 70, assinala "a clara diferenciação de campos epistemológicos". Em realidade, como já dissemos acima, o impulso maior em direção a um campo de estudos sociológicos em saúde tem seu início nos anos 70. Sem dúvida, os antecedentes mais próximos desta década são marcados pela obra de M ichel Foucault, que iluminou o campo da doença e da 
medicina com duas obras dos anos 60 que se tornariam referência até os nossos dias - a História da loucura (1961) e o N ascimento da clínica (1963). Destaque-se, também, desse período, a publicação de Bastide (1968) Sociologia das doenças mentais, referência para o estudo das doenças mentais.

No início da década de 1970, aparece a primei ra coletânea de textos organizada por Claudine Herzlich (1970), exclusivamente formada pela tradução de textos americanos de diversos autores e que abordavam os mais variados aspectos da sociologia médica, tais como: definições sociais da doença e das práticas, instituições de saúde. Principalmente com H erzlich, que já havia publicado, em 1969, a sua importante pesquisa sobre as representações sociais e Luc Boltanski, com a pesquisa sobre a puericultura (1968) e depois com o estudo sobre a descoberta da doença (1969) e os usos sociais e 0 corpo (1971) são lançadas as bases dos estudos contemporâneos da sociologia da saúde (Boltanski, 1979).

Dois anos depois, François Steudler (1972) publicaria uma outra coletânea, como guia de leitura e de textos selecionados, composta das seguintes seções: 1) doença, cultura e sociedade; 2) a relação terapêutica; 3) o hospital e a profissão médica; e 4) economia e políticas de saúde. Diferente do livro anterior, o autor, além de elaborar detalhada revisão sobre cada grande tema, oferece uma orientação bibliográfica de textos americanos e franceses e completa o livro com excertos de diversos autores como Canguilhem, Foucault, Parsons, Renee Fox, Valabrega, Goffman, Fabre, Perrin e outros.

Logo em seguida, a Revue Française de Sociologie, no 14 (1973) publicaria um número especial sobre Sociologie M édicale. Com introdução de J acques $M$ aître e a colaboração de sete autores: Pierre Royer ( $M$ édicine e societé), François Steudler (H ôpital, profession médicale ete politique hospitalière), Claudine H erzlich (Types de clientèle et fonctionnement de l'institution hospitalière), Antoinette Chauvenet (Ideologies et status professionnels chez les médecins hospitaliers), Jean Duhart e Jacqueline Charton-Brassard (Réforme hospitalière et soin infirmier sus ordonnance médicale), Roland Pressat (Surmortalité biologique et surmortalité sociale), Robert Castel (Vers les nouvelles frontières de la médicine mentale), este número da revista constitui um documento importante na trajetória da sociologia médica francesa, pois, além dos artigos, há uma extensa revisão bibliográfica do que, até então, havia sido publicado em francês. Da mesma forma, o número especial da Social Science $\&$ M edicine, 20 (2) de 1985, iria trazer algumas contribuições relevantes, tais como os "usos sociais da doença", de Dodier; sobre o paciente em hemodiálise, de Waissman; 0 aprofundamento e ampliação da concepção clássica do papel de doente, de H erzlich e Pierret, a comparação entre o sistema hospitalar francês e canadense, de Pourvourville e Renaud; relações dos procedimentos administrativos e as práticas hospitalares, de Cabridain e a descrição das práticas diárias dos médicos generalistas, de Letourmy. $\mathrm{Na}$ mesma década, duas referências, embora não especificamente no campo da sociologia, mas da antropologia, merecem citação: a publicação de François Laplantine (1986) da Anthropologie de la maladie, com a proposta de um estudo etnológico dos sistemas de representações etiológicas e terapêuticas na sociedade ocidental e 0 material organizado por Anne Retel Laurentin (1987), denominado Étiologie et Percepction de la $M$ aladie dans les soci étés modernes et traditionnelles, resultado do 10 Colóquio $\mathrm{N}$ acional de Antropologia M édica. Recentemente, as Actes de la Recherche en Sciences Sociales organizaram dois números temáticos, em 1987, oo 68, sobreÉpidemies, malades et médecinse, em 2002, no 143 , abordando M édecins, patients et politiques de santé.

Caberia, ainda, a Claudine H erzlich, juntamente com Philippe Adam, publicar, em 1994, o primeiro livro-texto francês de sociologia médica (Adam e Herzlich, 2001). Além de referências à bibliografia internacional, os autores recuperam a literatura francesa mais recente sobre a sociologia da doença e da medicina. A partir de uma perspectiva tanto histórica como sociológica, analisam a evolução histórica das doenças no 0 cidente, resultando nas atuais condições sanitárias e, de outro lado, investigaremos a emergência da medicina científica moderna (...), descrevendo, em seguida, os problemas de saúde das populações e seus determinantes sociais. Aborda a doença no campo social atual, relacionada aos atores - doentes e equipes médicas; 0 funcionamento do hospital e a doença "em todos os lugares da vida social" - na família e nos espaços públicos.

Este é um exemplo de amadurecimento da área, ocorrido de forma tardia, comparando-se aos Estados Unidos. Segundo O rfali (2001) foi ofuscada por um contexto que prestigiava a clínica e que nos anos 70 aparece numa conjunção com as primeiras controvérsias sobre o poder mé 
dico e os primeiros estudos sobre as reformas hospitalares e médicas, que se reflete na temática investigada por diversos sociólogos. Em realidade, a sociologia médica francesa, nesse momento, caracterizava-se muito mais por preocupações teóricas do que empíricas, quando comparada às pesquisas americanas, porém o que a diferencia é a priorização do discurso sobre as práticas como fonte de informação para análise. É aqui que a herança de Foucault torna-se aparente. $A$ análise do discurso que circunda a doença $e$ a saúde, assim como do discurso médico em geral são os temas dominantes da sociologia médica "à la française". O utra característica desse campo na França, apontada por H erzlich (1985), é que ele não se desenvolveu como área de ensino, mas de pesquisa, não tendo "recebido reconhecimento acadêmico" e com pouca presença nos currículos de medicina. Para a autora, a situação francesa é diversa da americana - sem conflitos se a disciplina deve ser chamada de sociologia na ou da medicina; sem maiores compromissos com o mundo médico, os sociólogos franceses têm estado livres para perseguir uma abordagem especificamente das ciências sociais para a saúde, doença e medicina, e dentro da tradição da sociologia francesa de não se definir como especialistas, parecem não se sentirem afastados do núcleo principal da sociologia edas suas orientações teóricas centrais.

\section{Comentários finais}

0 presente trabalho não tem a pretensão de traçar um quadro exaustivo da produção científica da sociologia médica norte americana, britânica e francesa. 0 objetivo foi o de elaborar um panorama geral, fixando os momentos marcantes da trajetória do campo e das principais contribuições. A sociologia médica contemporânea nos Estados U nidos apresenta-se altamente diversificada em sua temática, o que se tornou também uma característica em outros países, como na Grã-Bretanha e, em menor extensão, na França.

Do ponto de vista das escolas de pensamento que orientam essa produção científica, há, no momento, uma perspectiva pluralista, embora seja difícil alcançar um nível maior de integração teórica e metodológica. Observa-se a preocupação de repensar as questões teóricas, no marco da sociologia do conhecimento, como é o caso da análise de W hite (1991), que situa como grandes espaços de construção teórica as contribuições advindas de Parsons, dos marxistas, do trabalho de Fleck eFoucault e da posição feminista. Ressalta o impacto do construcionismo social e de que, do ponto de vista epistemológico, não se trata de escolher entre relativismo e objetivismo, mas entre um relativismo pessimista e um relativismo otimista e que a sociologia da saúde com seu foco sobre mudanças a longo prazo, sobre os microprocessos do comportamento na saúde e sobre os macroprocessos de respostas societárias às epidemias fornece uma fértil arena para que este debate seja realizado. Este éum ponto também elaborado por Annandale (1998) em relação à Grã-Bretanha e Adam e Herzlich (2001), quando analisam a situação do campo na França.

Para muitos sociólogos, atualmente, a clássica distinção feita por Straus (1954) entre sociologia na medicina e sociologia da medicina perdeu o seu significado original. Para W ardwell (1982), talvez seja tempo de parar com a preocupação de se o trabalho de um sociólogo da medicina é na sociologia da medicina ou da sociologia da medicina. Para Levine (1987), observando a nossa relação com a medicina, ela pode nos fornecer uma oportunidade histórica para nos desembaraçarmos da distinção historicamente muito útil, mas agora al go nebulosa, entre a sociologia na medicina e sociologia da medicina. Q uando focalizamos sobre a qualidade de vida dos pacientes, os interesses da sociologia e da medicina convergem. Podemos apropriadamente seguir a su gestão de alguns nossos colegas ingleses, cujo ponto de partida é o de se pensar em uma sociologia com a medicina, e, naturalmente, com outros profi ssionais de saúde. Para Light (1992), a pesquisa sociológica básica é compatível com a pesquisa aplicada e de intervenção, mesmo considerando que elas partem de diferentes questões e variáveis. Cita que, em sua forma mais usual, os estudos da sociologia da doença, do comportamento na doença, do papel de doente e estresse foram abordados apoliticamente, e que a abordagem sociológica desses fenômenos constitui "um paradigma alternativo para o modelo biomédico". De outro lado, assinala que, embora muitos estudos sobre aspectos organizacionais sejam tecnicamente bons, não fazem uma ponte com a sociologia como disciplina mais abrangente, e, de um modo geral, são poucos aqueles que se voltam para os estudos sobre os sistemas de saúde na tradição sócio-histórica de Sigerist, Rosen ou Stern.

0 reconhecimento de que há necessidade de repensar o campo, inclusive com críticas muitas 
vezes contundentes, tem concorrido para iluminar os caminhos futuros da sociologia médica, como escreve Fox (1985): M inhas críticas ao estado atual da sociologia médica e minha insatisfação com ela são, como espero ter exposto, uma forma de divino descontentamento sociológico. Sua profissão de fé na sociologia ena sociologia médica é tocante e reflete o que pensam muitos outros profissionais dessas áreas: Eu gosto de ser socióloga. Esteémeu território. Eu não somente acredito por princípio, mas tenho encontrado, no plano real, que trabalhar como socióloga da medicina deu-me a oportunidade para estudar uma variedade de aspectos interessantes e versáteis da vida social e cultural, como bási cos e transcendentes. Também foi uma forma significante de contribuir para o conhecimento e a compreensão sociológica, para vibrante ensino e para humanitariamente capacitar o cuidado e a política médica.

A extensa produção acumulada e em desenvolvimento na sociologia médica norte-americana, a sua tradição teórica, mesmo que limitada, e o espírito crítico da nova geração de sociólogos e de muitos de seus veteranos pesquisadores e o não afastamento do core da sociologia são elementos que não podem deixar de ser lembrados nestas conclusões. Pescosolido e Kronenfeld (1995) foram extremamente oportunas ao lembrar que nossa premissa de que a agenda primeira da sociologia contemporânea estende-se na descrição e compreensão da transição que vai além da sociedade moderna e das formas assumidas pela sociedade industrial e das novas fundações e instituições da vida social são pontos-chave para a sociologia médica.

\section{Referências bibliográficas}

Adam P \& H erzlich C 2001. Sociologia da doença e da medicina. (Trad. de Laureano Pelegrin). Edusc, Bauru.

Annandale E 1998. The sociology of health \& medicine: a critical introduction. Polity Press, Cambridge.

Annandale E \& Field D 2001. M edical sociology in Great Britain, pp. 246-262. In Cockerham WC (ed.). The Blackwell Companion to medical sociology. Blackwell Publishers, Oxford.

Badgley RF \& Bloom S W 1973. Behavioral sciences and medical education: the case of sociology. Social Sciences \& M edicine 7:927-941.

Bastide R 1968. Sociologia das doenças mentais. (Trad. de Ramiro da Fonseca). Publicações Europa-América, Lisboa.

Becker HS, Geer B, Hughes EC \& Straus AL 1961. Boys in white - student culture in medical school. University of Chicago Press, Chicago, Illinois.

Becker HS 1963. Outsiders: studies in the sociology of deviance. Free Press, N ova York.

Blackwell E 1902. Essays in medical sociology. (2 vol.). Ernest Bell, Londres. 
Bloom SW 1986. Institutional trends in medical sociology. Journal of H ealth and Social Behavior 27:265-276.

Bloom SW 1990. Episodes in the institutionalization of medical sociology: a personal view. Journal of $\mathrm{H}$ ealth and Social Behavior 31:1-10.

Boltanski L 1968. Prime education et morale de classe. M outon et Cie., Paris.

Boltanski L [1969] (1979). As classes sociais e o corpo. (Trad. de Regina A. M achado). Graal, Rio de Janeiro.

Brown P 1995. Naming and framing: the social construction of diagnosis and IIIness. Journal of $\mathrm{H}$ ealth and Social Behavior (extra issue):34-52.

Chen M-S 1998. H oward Waitzkin: intelectual for the disadvantaged. Journal of $\mathrm{H}$ ealth and Social Behavior 39: 4-6.

Cockerham WC 1983. The state of medical sociology in the U nited States, Great Britain, W est Germany and Austria: applied vs. pure theory. Social Science and M edicine 17(20):1.531-1.527.

Cockerham WC 1988. M edical sociology, pp. 575-599. In Smelser NJ (ed.). H andbook of sociology. Sage Publications, Londres.

Cockerham WC (ed.) 2001. The Blackwell Companion to medical sociology. Blackwell Publishers, Oxford, UK.

Cook JA \& W right ER 1995. M edical sociology and the study of severe mental illness: reflections on past accomplishments and directions for future research. Journal of $\mathrm{H}$ ealth and Social Behavior (extra issue): 95-114.

Cuin C-H \& GresleF 1994. História da sociologia. (Trad. de Roberto Leal Ferreira). Ensaio, São Paulo.

Editor's note 1961. Journal of $\mathrm{H}$ ealth and $\mathrm{H}$ uman Behavior 2:59.

Ehrenreich B \& Ehrenreich J 1970. The american health empire: power, profits and politics. A report from the $\mathrm{H}$ ealth Policy Advisosry Center. Random House, NovaYork.

Field D \& Taylor S 1998. Sociological perspectives on health, illness and health care. Blackwell Science Ltd., Oxford.

Fox RC 1959. Experiment perilous: physicians and patients facing the unknown. Glencoe, III. Fee Press.

Fox RC 1985. Reflections and opportunities in the sociology of medicine. Journal of $\mathrm{H}$ ealth and Social Behavior 26:6-14.

Fox RC 1989. The sociology of medicine: a participant observer's view. Prentice Hall, Englewood Cliffs, N ova Jersey.

Frankenberg R 1974. Funcionalism and after? Theory and developments of social science applied to the health field. International Journal of H ealth Services 4:411427.

Freeman H \& Reeder L 1957. M edical sociology: a review of the literature. Sociologial American Review 22(1): 73-81.

Freidson E 1962. The sociology of medicine: a trend report and bibliography. Current Sociology 10(3):123-195.

Freidson E 1970. The profession of medicine: a study of the sociology of applied knowledge. University of Chicago Press, Chicago.

Freidson E 1983. Viewpoint: sociology and medicine: a polemic. Sociology of $\mathrm{H}$ ealth and IIIness 5:208-219.

Glaser B \& Straus AL 1965. A wareness of dying. Aldine, Chicago.

Goffman E 1973. Asylums. Penguin Books. M iddlesex, Inglaterra.

Gold M 1977. A crisis of identity: the case of medical so- ciology. Journal of $\mathrm{H}$ ealth and Social Behavior 18 : 160-168.

Gold M 1978. Reply to comment by Greene. Journal of Health and Social Behavior 19(1):117-118.

Gray BH \& Phillips SR 1995. M edical sociology and health policy: where are the connections? J ournal of $\mathrm{H}$ ealth and Social Behavior (extra issue):170-82.

Greene M G 1978. The crisis in medical sociology (Comment). Journal of $\mathrm{H}$ ealth and Social Behavior 19(1): 117.

H afferty FW \& Light DW 1995. Professional dynamics and the changing nature of medical work. Journal of $\mathrm{H}$ ealth and Social Behavior (extra issue):132-153.

Herzlich C 1970. M édicine, maladie et société. M outon, Paris-La-Haye.

Herzlich C 1985. Sociology of health and illness in France, retrospectively and prospectively. Social Science and M edicine 20(2):121-122.

H ollingshead A 1973. M edical sociology: a brief review. M ilbank M emorial Fund Quarterly 51(1):531-541.

Johnson ML 1975. Medical sociology and sociological theory. Social Science and M edicine 9:227-23

LaplantineF 1986. Anthropologie de la maladie. Payot, Paris

Laurentin AR (coord.) 1987. Étiologie et perception de la maladie. L'H armattan, Paris.

Levine S 1987. The changing terrains in medical sociology: emergent concern with quality of life. Journal of Health and Social Behavior 228:1-6.

Levine $S$ 1995. Time for creative integration in medical sociology. Journal of $\mathrm{H}$ ealth and Social Behavior (extra issue): :1-4

Ligth DH 1992. Introduction: strengsthening ties between specialities and the discipline. American Journal of Sociology 97(4):909-917.

Link BG \& Phelan J 1995. Social conditions as fudnamental causes of disease. Journal of $\mathrm{H}$ ealth and Social $\mathrm{Be}$ havior (extra issue):80-94.

M aitre J 1973. La conjoncture de la recherche française en sociologie médicale. Revue Française de Sociologie 14(numéro spécial).

M clntire Ch 1894. The importance of the study of medical sociology. N ew England Journal of M edicine 211(18): 819-823.

M echanic D 1968. M edical sociology: a selective view. Free Press, Nova York.

Mechanic D 1989. Medical sociology: some tensions among theory, method and substance. Journal of $H$ ealth and Social Behavior 30:147-160.

M erton RK, Reader GG \& Kendall PL 1957. The studentphysician - introductory studies in the sociology of medical education. $\mathrm{H}$ arvard U niversity Press, Cambridge, $M$ ass.

Navarro V 1976. M edicine under capitalism. Croom H elm, Londres.

N avarro V 1982a. Imperialism, health and medicine. Pluto, Londres.

N avarro V 1982b. The crisis of the internacional capitalist order and its implications for the welfare state. International Journal of H ealth Services 12:169-191

Navarro V 1983. Radicalism, marxism and medicine. International Journal of $\mathrm{H}$ ealth Services, 13.

Nunes ED 1995. Atitudes leigas relacionadas à doença: revisando a literatura. Campinas. Relatório/CN Pq.

Nunes, ED 1999. Sobre a sociologia da saúde. Hucitec, São Paulo.

Orfali K 2001. The French paradoxes, pp. 263-286. In 
Cockerham WC (ed.). The Blackwell Companion to medical sociology. Blackwell Publishers: Oxford.

Parsons T 1967. The social system. The Free Press. Glencoe, III.

Perlin LI 1992. Structure and meaning in medical sociology. Journal of $\mathrm{H}$ ealth and Social Behavior 33:1-9.

Pescosolido BA \& Kronenfeld JJ 1995. Health, illness, and healing in an uncertain era: challenges from and for medical sociology. Journal of $\mathrm{H}$ ealth and Social Behavior (extra issue):5-33.

Pflanz M 1974. A critique of Anglo-American medical sociology. International J ournal of $\mathrm{H}$ ealth Services 4(3): 565-574.

Reader G \& Goss ME 1959. The sociology of medicine. In M erton RK et al. (eds.). Sociology Today, Col. 1, Basic Books, N ova York.

Reader $\mathrm{G}$ 1963. Contributions to sociology to medicine. In Freeman $\mathrm{H}$, Levine $\mathrm{S} \&$ Reeder $\mathrm{L}$ (eds.). H andbook of medical sociology. Prentice-H all, Englewood Cliffs, NJ.

Reydi A 1984. Marxist funcionalism in medicine: a critique of the work of Vicente $\mathrm{N}$ avarro on health and medicine. Social Science \& M edicine 19(9):897-910.

Robinson D 1971. The process of becomin ill. Routledge \& Kegan Paulo, Londres.

Robinson D 1973. Patients, practitioners \& medical care: aspects of medical sociology. William Heinemann M edical Books, Londres.

Scambler G \& Higgs P (ed.) 1998. M odernity, medicine and health - medical sociology towards 2000 . Routledge, Londres.

Scheff T 1966. Being mentally ill. Aldine, Chicago.

Simmons L\& Wolff H 1954. Social science in medicine. Russel Sage, N ova York.

Stacey M \& H omans H 1981. The sociology of health and illness: its present state, future prospects, and potencial for health research. Sociology - The Journal of British Sociologial Association 12(2):281-307.
Stern BJ 1959. Toward a sociology of medicine. In Stern BJ. H istorical sociology: selected papers. Citadel Press, NovaYork.

Steudler F 1972. Sociologiemédicale. Armand Colin, Paris. Straus R 1957. The nature and status of medical sociology. American Sociological Review 22:200-204.

Suchman EA 1963. Sociology and the field of Public $\mathrm{H}$ ealth. Russel Sage, Nova York.

Susser M \& Watson W 1962. Sociology in M edicine. Oxford, Londres.

Thoits PA 1995. Stress, coping, and social support processes: where are we? What next? J ournal of $\mathrm{H}$ ealth and Social Behavior (extra issue):53-79.

Tuckett D (Ed.) 1976. An introduction to medical sociology. Tavistock Publications, Londres.

Waitzkin H 1998. Is our work dangerous? Should it be? Journal of $\mathrm{H}$ ealth and Social Behavior 39:7-17.

Waitzkin H \& Waterman B 1974. The exploitation of illness in capitalist society. Bobbs-M errill, Indianápolis.

WarbasseJ 1909. M edical sociology. Appleton, Nova York.

Wardwell W 1982. The state of medical sociology - a review essay. Sociology Q uarterly 23:563-571.

White K 1991.The sociology of health and illness. Current Sociology 39(2):1-123.

Zola IK 1966. Culture and symptoms: an analysis of patients's presenting complaints. American Sociological Review 31:615-630.

Zola IK 1973. Pathways to the doctor: from person to patient. Social Science \& M edicine 7(9):677-689.

Zola IK 1991. Bringing our bodies and ourselves back in: reflections on a past, present and future of "medical sociology". Journal of $\mathrm{H}$ ealth and Social Behavior 32: 1-16.

Artigo apresentado em 7/9/2002

Aprovado em 22/10/2002

Versão final apresentada em 28/11/2002 